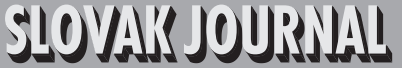 \\ $0\}$

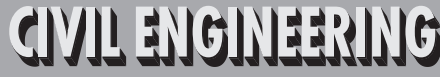

Vol. XX, 2012, No. 3, 15 - 26, DOI: 10.2478/v10189-012-0014-7

K.V. VENKATESHA, K. BALAJI RAO, S.V. DINESH, B.H. BHARATKUMAR, M.B. ANOOP, BALASUBRAMANIAN, S.R., NAGESH R. IYER

\section{EXPERIMENTAL INVESTIGATION OF REINFORCED CONCRETE BEAMS WITH AND WITHOUT CFRP WRAPPING}

\section{ABSTRACT}

This paper presents the results of experimental investigations on six reinforced concrete beams, with three different shear span-to-depth ratios, which were tested under two-point loading. The aim of the work was to study the efficacy of Carbon Fibre Reinforced Polymer (CFRP) strips in enhancing shear capacity and/or changing the failure mode from brittle shear failure to ductile flexural failure. The results of the study indicate that while there is a marginal increase in first crack and ultimate loads, it is possible to achieve a change in the failure mode, and the monitored strain gange data can be used to explain the failure pattern observed.

K.V. VENKATESHA
email: venkateshkv020@gmail.com
Research field: Reinforced concrete; CFRP wrapping
S.V. DINESH
email: dinesh@sit.ac.in
Research field: Soil Dynamics; Discrete element mod-
elling; Fracture of concrete
Address:
Department of Civil Engineering,
Siddaganga Institute of Technology,
Tumkur, Karnataka,
India - 572103.
K. BALAJI RAO
email: balaji@serc.res.in; balajiserc1@yahoo.com
Research field: Stochastic mechanics; Risk-consistent
design; Hybrid uncertainty modelling
B.H. BHARATKUMAR
email: bharat@serc.res.in
Research field: High performance concrete com-
posites including fibre reinforced concrete; Fracture
mechanics of concrete
M.B. ANOOP
email: anoop@serc.res.in
Research field: Computational mechanics; Fuzzy and fuzzy-
random modelling; Durability-based service life design
BALASUBRAMANIAN, S.R.
email: srbala@serc.res.in
Research field: Structural brick masonry buildings:
lateral load analysis, vulnerability analysis and retrofit-
ting strategies
NAGESH R. IYER
email: nriyer@serc.res.in
Research field: Computational structural mechanics;
Damage tolerant design; Innovative sustainable and/
or new engineered materials and novel methodologies
for retrofitting
CSIR - Structural Engineering Research Centre,
India - 600113.

KEY WORDS

- Reinforced concrete,

- Carbon fibre,

- Shear strength,

- Failure mode,

- Cracking load,

- Ultimate load. 


\section{INTRODUCTION}

The use of Fibre-Reinforced Polymers (FRPs) for the rehabilitation of existing reinforced concrete (RC) structures has grown very rapidly over the last few years. Research has shown that FRPs can be used very efficiently in strengthening RC beams that are weak in flexure, shear or torsion [1-14]. Strengthening with externally bonded FRP sheets has been shown to be applicable to many types of RC structural elements. FRP sheets may be: i) adhered to the tension side of structural members (e.g., slabs or beams) to provide additional flexural strength, ii) adhered to the sides of webs of joists and beams to provide additional shear strength, iii) wrapped around columns to provide additional shear strength, and iv) wrapped around columns to increase concrete confinement and thus increase the strength and ductility of columns. FRP wraps increase the shear strength of RC beams and columns [15-18]. The additional shear strength is obtained by orienting the fibres in a direction that is transverse to the axis of the RC member or perpendicular to the shear cracks [19-20]. The primary advantage of the use of FRP reinforcement in RC structures is that it has better corrosionresistant properties compared to conventional steel.

The purpose of the present study was to investigate the strength and behaviour of reinforced concrete beams wrapped/strengthened with a discrete U-type wrapping of one layer of Carbon Fibre-Reinforced Polymer (CFRP) strips. Towards this, six simply-supported singly- reinforced concrete beams of a rectangular cross-section were cast and tested under two-point loading. Three shear span-to-effective depth ratios $(\mathrm{a} / \mathrm{d})$ were chosen so that two control beams would fail in shear, while the third one would fail in flexure. For a given $(\mathrm{a} / \mathrm{d})$ ratio, one control beam and one wrapped beam were considered.

\section{EXPERIMENTAL INVESTIGATIONS}

The main focus of this investigation was to examine the efficacy of discrete CFRP wraps in improving the flexural/shear strength of simply-supported singly-reinforced concrete beams. From a review of the literature it has been found that shear reinforcement and shear span-to-depth ratios are, amongst other things, two important parameters to be considered in studying the efficacy of CFRP wraps. Keeping these in mind, a comprehensive experimental program involving the testing of six beams (three wrapped and three control beams) in two-point bending, was planned. All the beams were designed according to IS 456-2000 [21]. The dimensions of the beams were $100 \mathrm{~mm} \times 200 \mathrm{~mm} \times 1500 \mathrm{~mm}$, with two $12 \mathrm{~mm}$ diameter bars as main reinforcements, two $6 \mathrm{~mm}$ diameter bars as hanger bars, and $6 \mathrm{~mm}$ diameter bars as two-legged stirrups with a clear cover of $25 \mathrm{~mm}$. Three stirrup spacings were considered in the present investigation (i.e., $100 \mathrm{~mm}, 120 \mathrm{~mm}$ and $125 \mathrm{~mm}$, with a design maximum spacing of $126 \mathrm{~mm}$ ). Figure 1 shows the

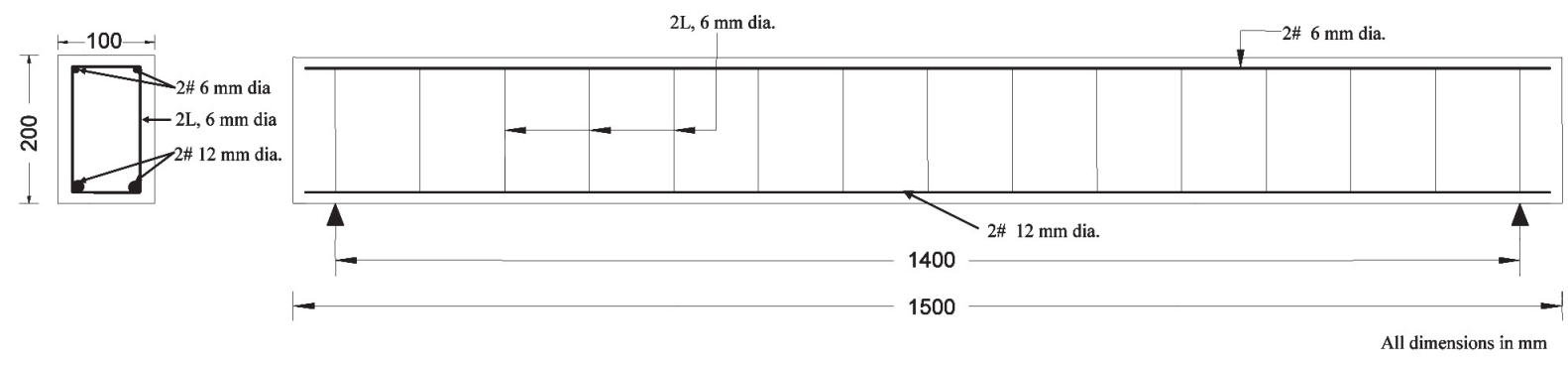

Fig. 1 Longitudinal and cross-sections of the beam.
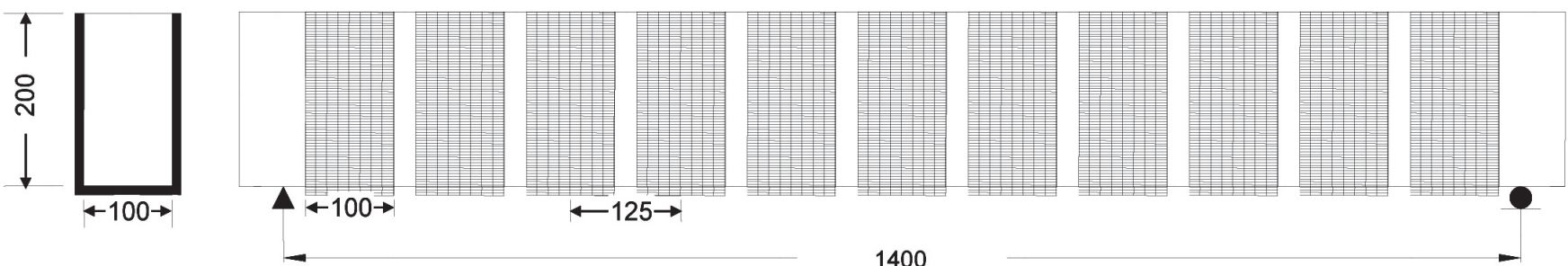

All dimesions are in $\mathrm{mm}$

Fig. 2 Strengthening scheme using CFRP wrapping. 
2012/3 PAGES $15-26$

Tab. 1 Details of the beams considered.

\begin{tabular}{|c|c|c|c|c|c|c|}
\hline \multirow{2}{*}{$\begin{array}{c}\text { Beam } \\
\text { designation }\end{array}$} & \multirow{2}{*}{$a / d *$} & \multirow{2}{*}{$\begin{array}{c}\text { Mean cube } \\
\text { compressive strength } \\
\text { of concrete }(\mathrm{MPa}) * *\end{array}$} & \multirow{2}{*}{ Beam type } & \multicolumn{2}{|c|}{ Shear reinforcement } & \multirow{2}{*}{$\begin{array}{l}\text { No. of CFRP } \\
\text { layer }\end{array}$} \\
\hline & & & & Steel stirrups & CFRP & \\
\hline SB1 & \multirow{2}{*}{2.57} & \multirow{2}{*}{47.52} & Control & 6mm ф@100 mm c/c & $\neg \neg \neg$ & - \\
\hline WSB1 & & & Wrapped & 6mm ф@100 mm c/c & U-wrap ${ }^{\#}$ & one ply $90^{\circ}$ \\
\hline SB2 & \multirow{2}{*}{1.85} & \multirow{2}{*}{46.57} & Control & 6mm ф@120 mm c/c & $\neg \neg \neg$ & - \\
\hline WSB2 & & & Wrapped & 6mm ф@120mm c/c & U-wrap ${ }^{\#}$ & one ply $90^{\circ}$ \\
\hline SB3 & \multirow{2}{*}{1.71} & \multirow{2}{*}{48.77} & Control & 6mm ф@125 mm c/c & $\neg \neg$ & - \\
\hline WSB3 & & & Wrapped & 6mm ф@125 mm c/c & U-wrap ${ }^{\#}$ & one ply $90^{\circ}$ \\
\hline
\end{tabular}

(Note: * - shear span (a) to effective depth (d) ratio

** - based on tests on three nominally similar cubes

\# - U-wrapping with strips $100 \mathrm{~mm}$ wide @125 mm c/c)

Tab. 2 Properties of reinforcing bars.

\begin{tabular}{|c|c|c|c|c|c|}
\hline Reinforcing bar & $\begin{array}{c}\text { Mean elastic modulus } \\
\mathbf{E}(\mathbf{M P a}) *\end{array}$ & $\begin{array}{c}\text { Mean diameter } \\
(\mathbf{m m})\end{array}$ & $\begin{array}{c}\text { Mean yield stress } \\
\boldsymbol{f}_{\mathbf{y}}(\mathbf{M P a}) *\end{array}$ & $\begin{array}{c}\text { Mean ultimate } \\
\text { strength } \boldsymbol{f}_{\mathbf{u}}(\mathbf{M P a}) *\end{array}$ & $\begin{array}{c}\text { Mean \% } \\
\text { elongation* }\end{array}$ \\
\hline Main & $2.02 \times 10^{5}$ & 11.94 & 473.33 & 620.26 & 24.33 \\
\hline Stirrup/ Hanger & $2.22 \times 10^{5}$ & 6.24 & 387.0 & 555.86 & 11.81 \\
\hline
\end{tabular}

(Note: *- based on tests on three nominally similar bars)

longitudinal and cross- sectional details of a typical beam. The mix was designed according to ACI 211.4R:1993, and the mix proportion was obtained as $1: 2.31: 2.60$ with a water-cement ratio of 0.45 . Two different types of coarse aggregates were used in the proportion: $60 \%$ of $20 \mathrm{~mm}$ and $40 \%$ of $10 \mathrm{~mm}$. The Carbon Fibre Reinforced Polymer (CFRP) strips of a width of $100 \mathrm{~mm}$ and a length of $500 \mathrm{~mm}$ (i.e., $2 \times 200+100 \mathrm{~mm}$ ) were wrapped (U-wrapped) around three beams with a centre-to-centre spacing of $125 \mathrm{~mm}$ (Fig. 2). The CFRP wraps used had a Young's modulus of $330 \mathrm{GPa}$ and a tensile strength of $1.80 \mathrm{GPa}$ [9]. Table 1 gives the details of the specimens considered in this experimental investigation, and Table 2 gives the properties of the reinforcing bars obtained based on the experimental investigations. Strain gauges of a length of $2 \mathrm{~mm}$ were embedded on the stirrup reinforcement in the shear span for measuring the strain (see Fig. 3).

For each casting (consisting of a control beam and the beam to be wrapped), three $100 \mathrm{~mm}$ cubes were cast as companion specimens. The casting of the beams and the companion specimens were carried

\section{NL}

NR

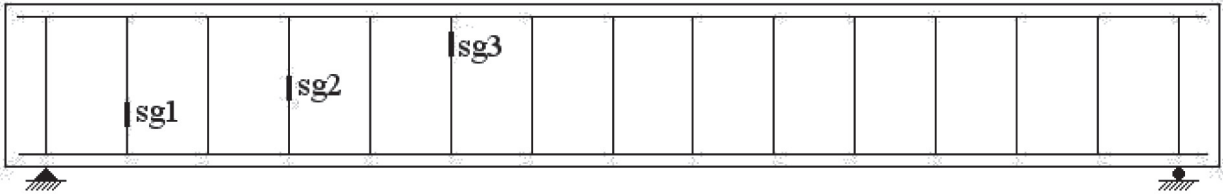

SL.

SR

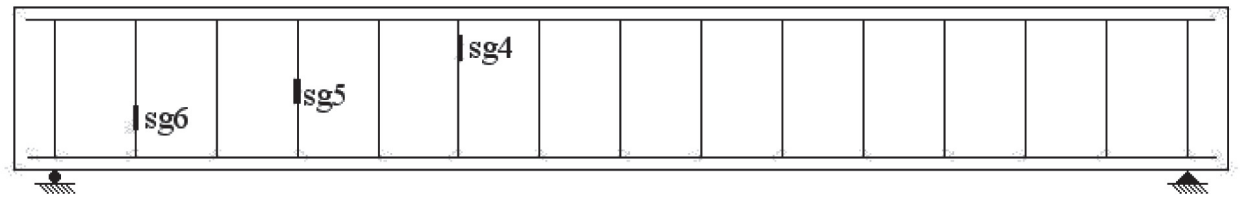

Fig. 3 Locations of embedded strain gauges (2mm gauge length) on stirrup ( $N$ and $S$ denote the North and South faces of the beam, respectively; $L$ and $R$ denote left and right ends, respectively). 

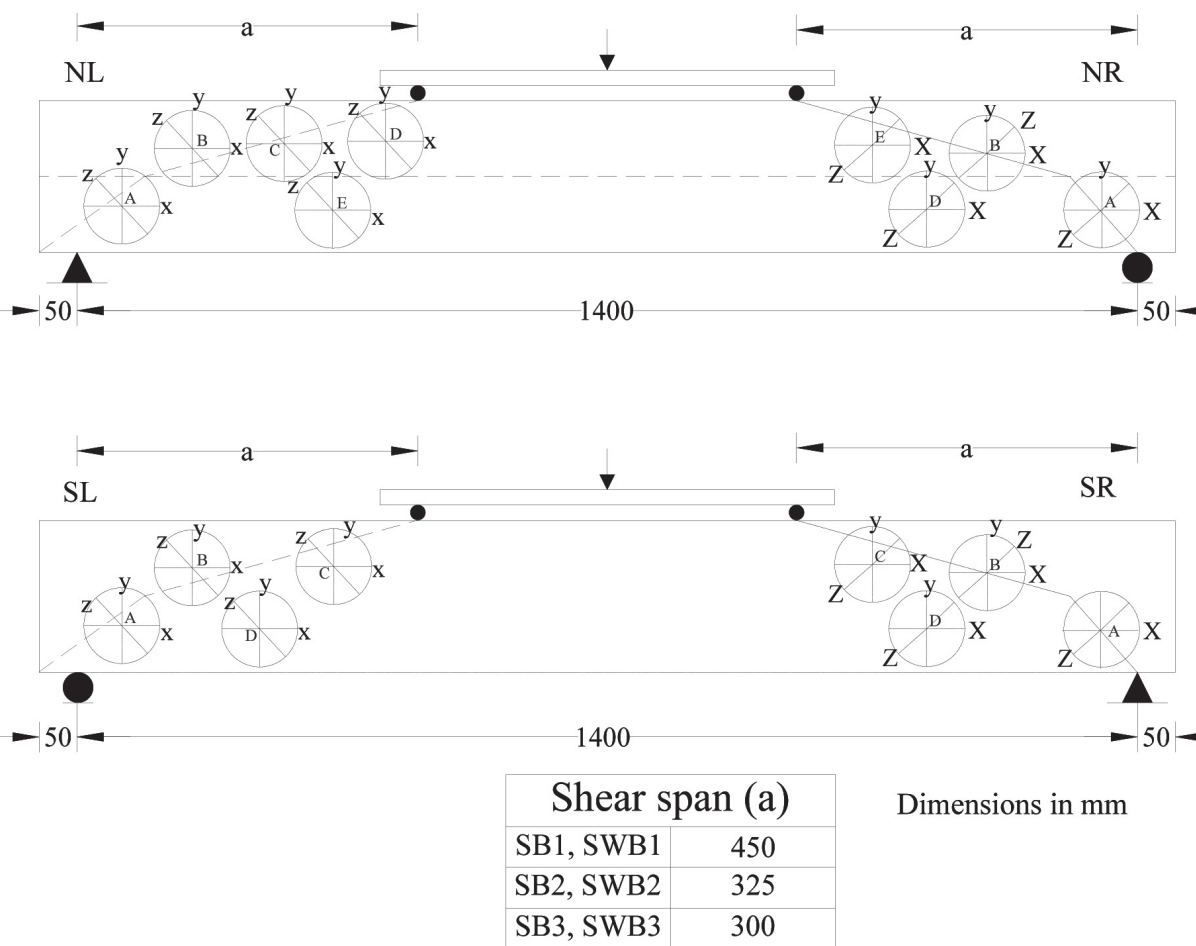

Fig. 4 Arrangement of demec points for measuring surface strains on north and south faces of Beam SB1.

out at the Advanced Materials Laboratory of CSIR-SERC. The beam and the companion specimens were kept in their respective moulds for 24 hours and later demoulded. They were cured for 28 days in a curing pond.

The beam specimens were tested in the loading frames of the Structural Testing Laboratory of CSIR-SERC. In the case of the control beams, it was planned to measure the surface strains on the concrete in the shear zone along X-Y-Z as shown in Fig. 4. A Pfender gauge with a least count of $1 / 1000$ strain units was used to measure the surface strains. However, for the wrapped beams, the demec points could not be pasted since the surface is smooth, and rubbing the surface would damage the wrap. Hence, for the wrapped beams, electrical resistance gauges (having a 30 $\mathrm{mm}$ gauge length) were pasted on the surface to measure the surface strains in the shear span (in the direction of the fibre) and in the region of the constant bending moment (perpendicular to the direction of the fibre) as shown in Fig. 5. Three strain gaugebased transducers, having a least count of $0.01 \mathrm{~mm}$ (capable of measuring a maximum deflection of $50 \mathrm{~mm}$ ) were placed under the load points and at the central section for measuring the deflections. All the electrical resistance strain gauges (six in the case of the control beams and sixteen in the case of the wrapped beams) and the displacement transducers were connected to a data logger. In the case of the control beams, the widths of the cracks were measured (if and when the cracks formed) at four different levels in the shear dominant region and at the level of the steel in the flexure dominant region (see Fig. 6). A crack gauge with a least count of $0.01 \mathrm{~mm}$ was used to measure the width of the cracks. In the case of the wrapped beams, the widths of the cracks were not measured since the cracking could not be traced. A typical test set-up is shown in Fig. 7.

The loading regime applied on the control beam was designed in such a way that there were at least three loading stages before the estimated first crack load and about five to six stages thereafter. However, whitewashing could not be done in the wrapped beams, and the demec points could not be pasted. Hence, the strain and deflection readings were taken using the automatic strain gauge data logger at increments of every $5 \mathrm{kN}$ load.

\section{EXPECTED BEHAVIOUR OF THE BEAMS TESTED}

Control Beams: Shear failure was not a consideration for the SB1 beam since the stirrup spacing adopted was $100 \mathrm{~mm}$, which is less than the maximum allowable spacing. Also, the $(\mathrm{a} / \mathrm{d})$ ratio for this 


\section{SIOVALS JOUSSILL \\ of $\mathrm{s}^{3}$

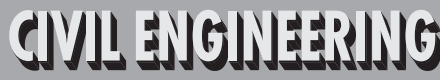

2012/3 PAGES $15-26$
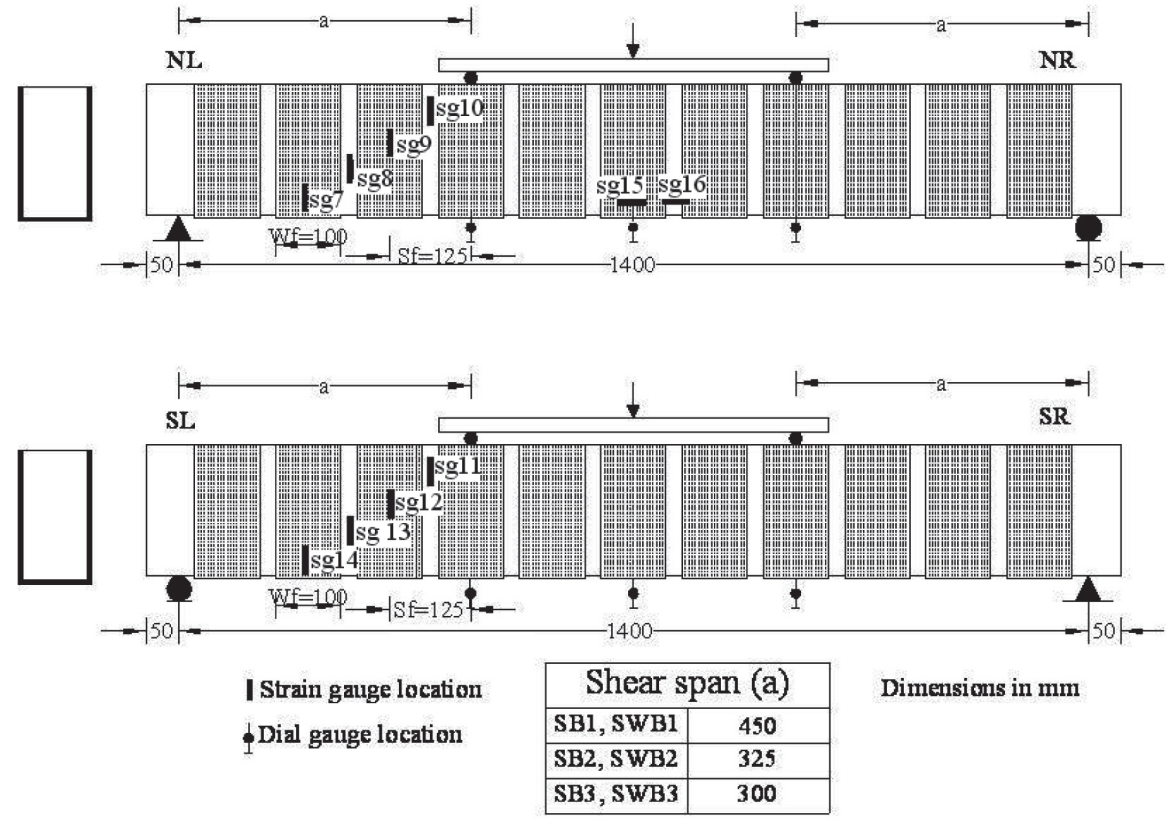

Fig. 5 Test set-up and locations of electrical resistance strain gauges (30 $\mathrm{mm}$ gauge length) on the surface of the wrapped beams.

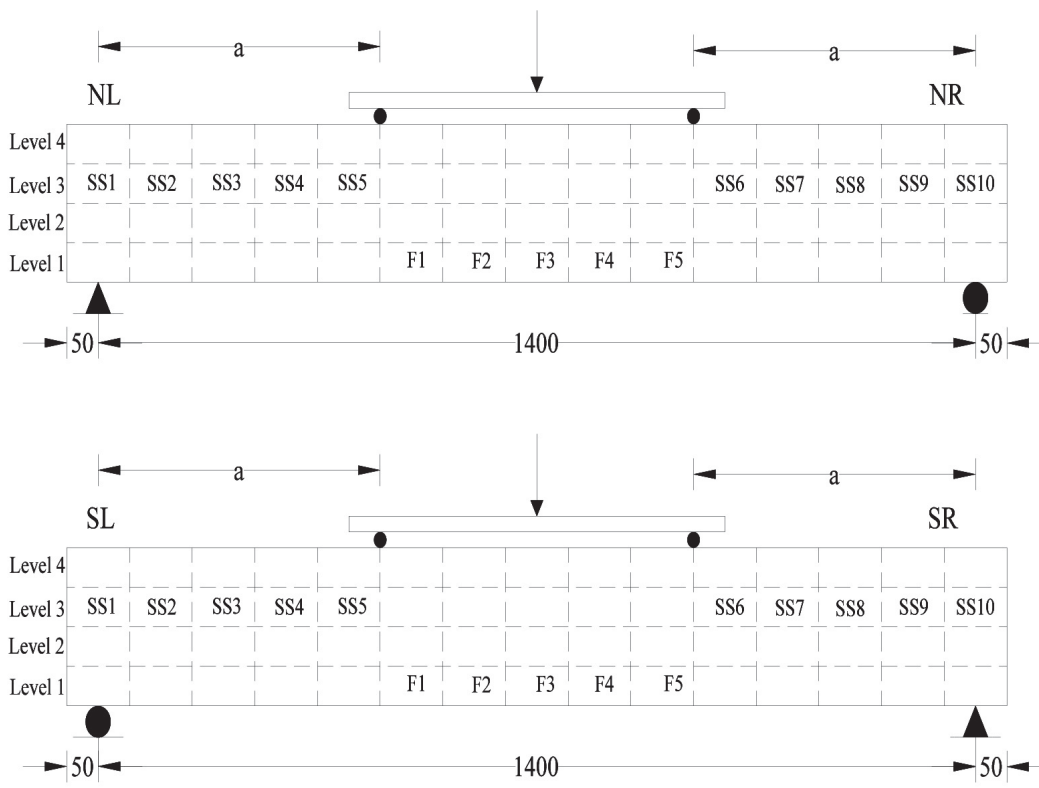

\begin{tabular}{|c|c|}
\hline \multicolumn{2}{|c|}{ Shear span (a) } \\
\hline SB1, SWB1 & 450 \\
\hline SB2, SWB2 & 325 \\
\hline SB3, SWB3 & 300 \\
\hline
\end{tabular}

Fig. 6 Sections marked on north and south faces of Beam SB1 for measuring crack widths. 


\section{IIOYASS JOUSSIAL \\ 0)

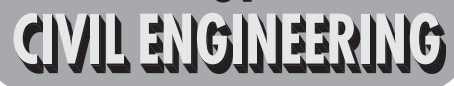

2012/3 PAGES $15-26$

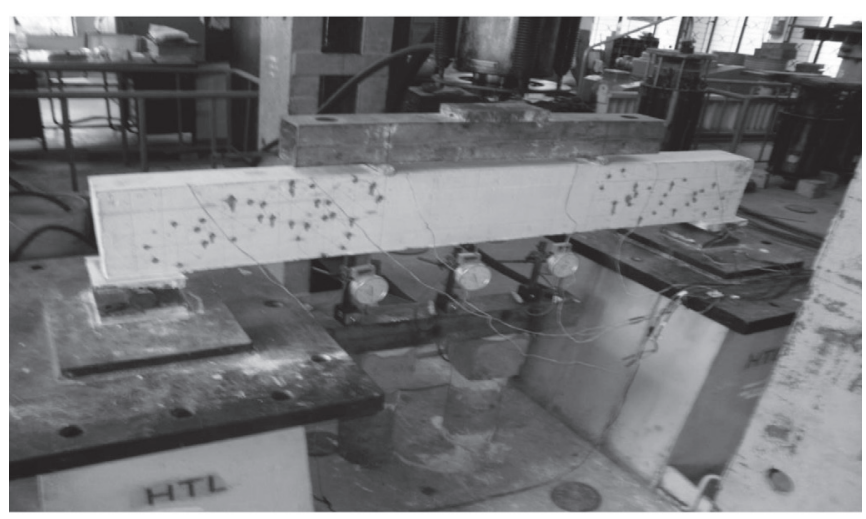

Fig. 7 Typical test set-up.

beam was 2.57, and hence a flexural failure was expected. However, in the SB2 and SB3 beams, a shear failure could have occurred since the stirrup spacing adopted (120 mm for SB2 and $125 \mathrm{~mm}$ for SB3) were closer to the maximum allowable spacing of $126 \mathrm{~mm}$. Also, the $(\mathrm{a} / \mathrm{d})$ ratio for SB2 was 1.85 , and a shear compression failure was expected in this beam. For SB3, the $(\mathrm{a} / \mathrm{d})$ ratio was 1.71 , and a diagonal tension (shear) failure was expected in this beam.

Wrapped Beams: The provision of the strips would enhance the shear strength of the beams and add to the shear resistance offered by the stirrups. Noting that a flexural failure was likely in the control beam (SB1), it was felt that the WSB1 beam might also have failed in flexure since the fibres in the flexure zone may not have provided significant resistance to the first crack formation. Also, the shear reinforcement provided in the WSB1 beam in the form of stirrups was less than the maximum allowable spacing. Thus, a flexure failure was expected with enhanced ductility and a marginal increase in the first crack strength for the WSB1 beam. From the values of the $(\mathrm{a} / \mathrm{d})$ and stirrup spacings, shear compression failure and diagonal shear failure were expected in the SB2 and SB3 control beams, respectively. However, it was felt that the WSB2 and WSB3 wrapped beams would not fail in the same modes since the shear zone had been strengthened. Thus, a failure in the zone of constant bending was more likely, perhaps with enhanced ductility and a marginal increase in the strength at the first crack.
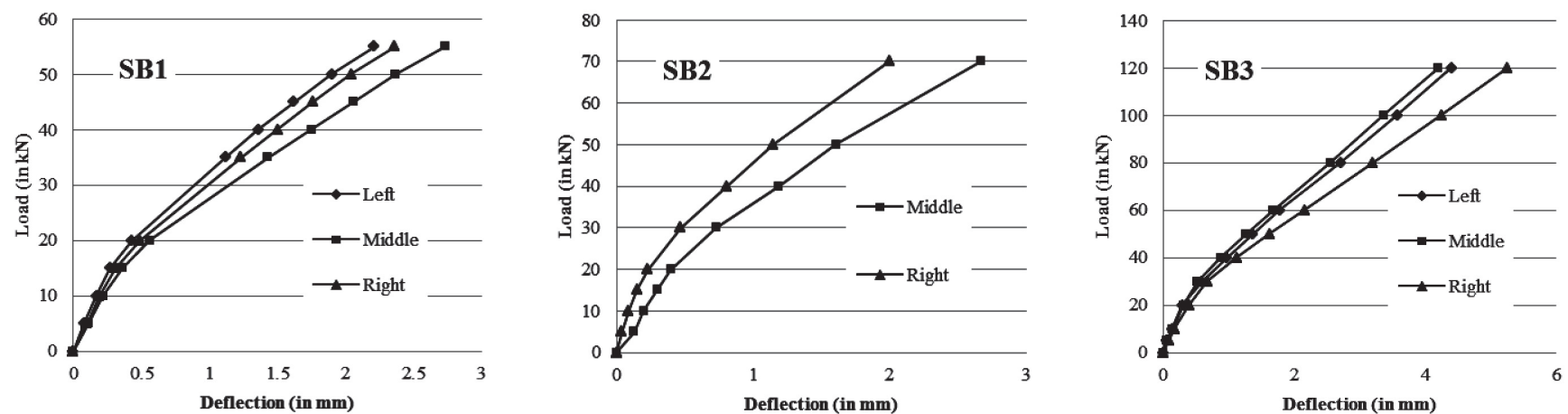

Fig. 8 Load-deflection curves for the three control beams.
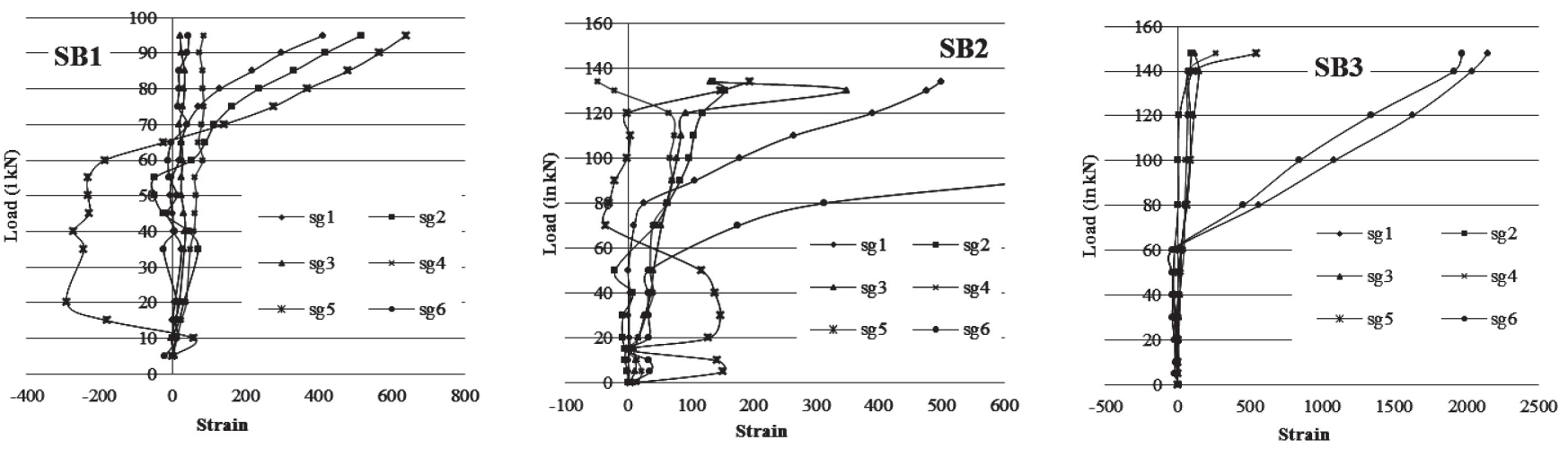

Fig. 9 Load versus strain (in $\mu \varepsilon$ ) curves for the three control beams (measured from the strain gauges pasted on stirrups; strains: positive - tension). 


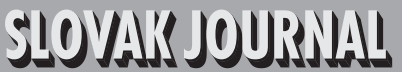

2012/3 PAGES $15-26$

\section{RESULTS AND DISCUSSIONS}

The deflections recorded at three different sections and the strains recorded on the stirrups for the three control beams are shown in Figs. 8 and 9, respectively. The deflections measured at three different sections (measured using displacement transducers), the strains on the stirrups and the surface strains for the three wrapped beams are shown in Figs. 10, 11 and 12, respectively. The failure patterns of the control beams are shown in Fig. 13 along with the failure patterns of the wrapped beams.

As a first step it was proposed to compare the first crack and ultimate loads of the control and the corresponding wrapped beams obtained from the tests. While testing the control specimens, the first crack load could not be exactly ascertained through visual examination of the surface of the beam since the testing frame was congested. Hence, the load-deflection curves and the readings from the strain gauges (which were located closer to the flexure zone) were considered for determining the first crack load. The values of the first crack and ultimate loads are presented in Table 3. It is noted from this table that there was no significant improvement in the first crack and ultimate strengths due to the wrapping. However, the failure mode changed with reference to the second and third control beams (for which $(\mathrm{a} / \mathrm{d})$ were 1.85 and 1.71 , respectively). The position of the dominant crack leading to failure depended on the (a/d) ratio, and the presence or absence of the wraps. While failure occurred in the SB2 and SB3 beams due to the propagation of the dominant crack from the shear zone, the failure of the respective wrapped beams (namely, WSB2 and WSB3) occurred due to the propagation of the cracks (almost vertically) in the flexure zone, albeit more or less under one of the load points. In the case of the wrapped beams, it is noted that at the time of the failure, the wrap, along with the thin layer of concrete, became separated (in the compression zone) on one or both of the faces, which led to an explosive failure due to the crushing of the concrete in the compression zone. In fact, in the case of the WSB1 beam, a lateral bending was also observed after the separation of the wrap. Along with the fact that there was no significant increase in the ultimate strengths of the beams, these observations suggest that the wraps in the shear zone should perhaps have been continuous and that the orientation of the fibres of the CFRP in the flexure zone should have
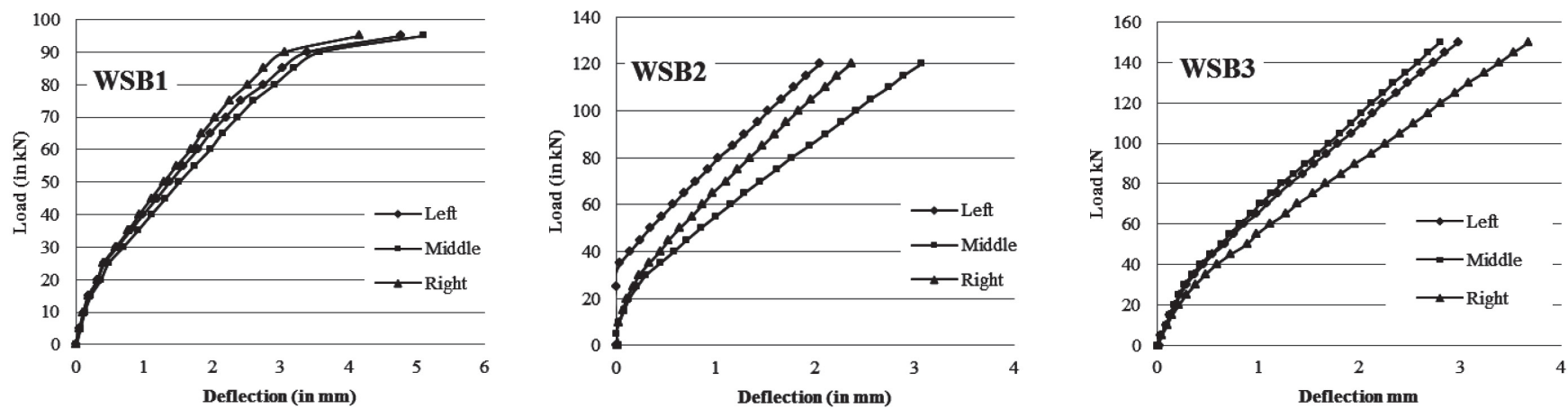

Fig. 10 Load-deflection curves for the three wrapped beams.
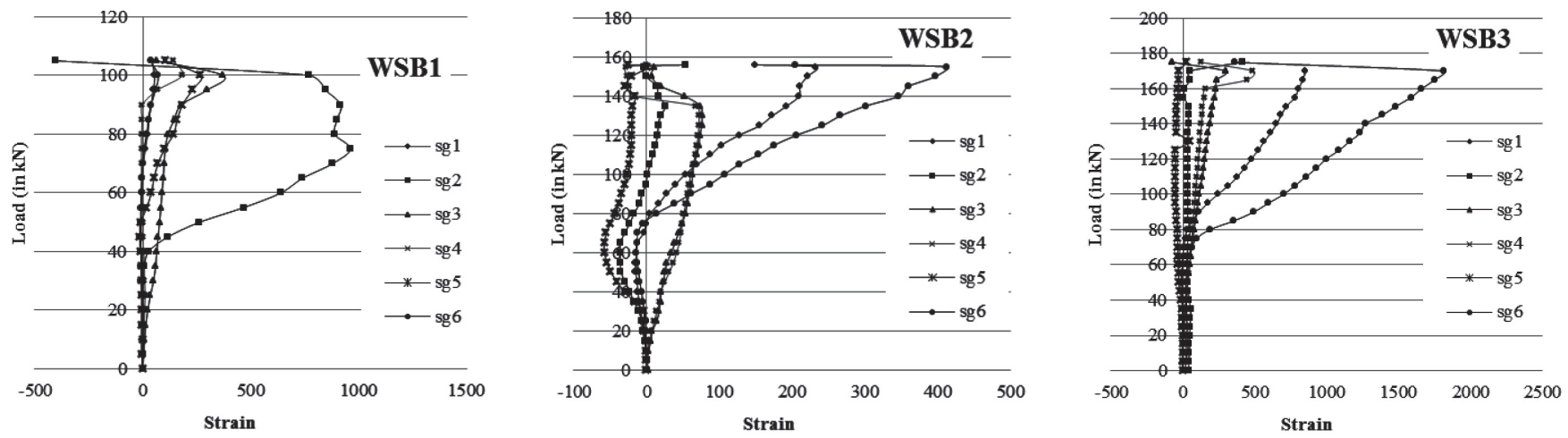

Fig. 11 Load versus strain (in $\mu \varepsilon$ ) curves for the three wrapped beams (measured from the strain gauges pasted on stirrups; strains: positive - tension). 

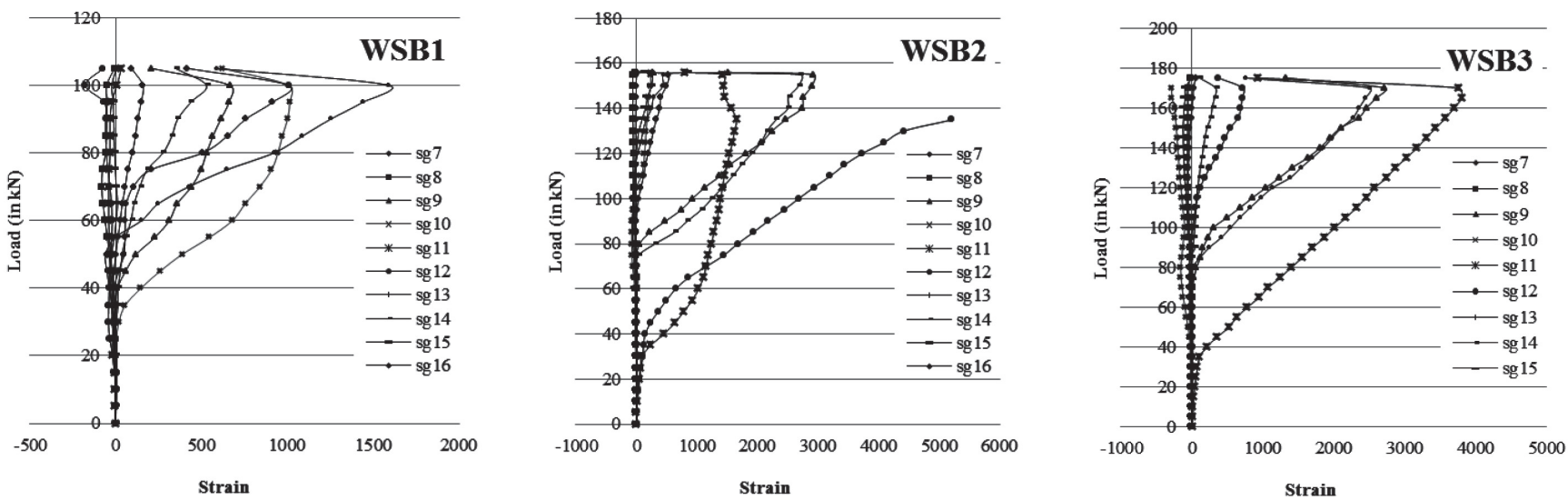

Fig. 12 Load versus strain (in $\mu \varepsilon$ ) curves for the three wrapped beams (measured from the strain gauges pasted on surface; strains: positive -tension).

Tab. 3 Experimental first crack- and ultimate- loads and the nature of failure.

\begin{tabular}{|c|c|c|c|c|}
\hline \multirow{2}{*}{$\begin{array}{c}\text { Beam } \\
\text { designation }\end{array}$} & $\begin{array}{c}\text { Load at initial crack } \boldsymbol{P}_{\mathbf{c r}}(\mathbf{k N}) \\
\text { curve }\end{array}$ & $\begin{array}{c}\text { Ultimate load } \\
(\mathbf{k N})\end{array}$ & Nature of failure \\
\cline { 2 - 3 } SB1 & $10-15$ & $10-15$ & 100.92 & Flexural failure \\
\hline WSB1 & $20(60 \%)$ & 20 & $106.08(5.11 \%)$ & $\begin{array}{c}\text { Failure due to bursting of concrete in } \\
\text { compression near load point }\end{array}$ \\
\hline SB2 & 18 & 18 & 134.92 & Shear compression failure \\
\hline WSB2 & $20-25(25 \%)$ & $20-25$ & $157.08(16.42 \%)$ & $\begin{array}{c}\text { Failure due to bursting of concrete in } \\
\text { compression zone under one of the load points }\end{array}$ \\
\hline SB3 & 25 & 25 & 149.08 & Diagonal Shear Failure \\
\hline WSB3 & $30(20 \%)$ & 30 & $176.08(18.11 \%)$ & $\begin{array}{c}\text { Failure due to explosive bursting of concrete in } \\
\text { compression zone under one of the load points }\end{array}$ \\
\hline
\end{tabular}

(Note: Values in brackets indicate the percentage increase from that of the corresponding control beam)

been parallel to the neutral plane of the beam; these schemes need further study. However, it is noted that the nature of the failure mode changed from a failure mode of shear to one of almost flexure by the wrapping scheme used in the present study.

A critical examination of the behaviour of both the control and wrapped beams was made using the strains recorded by the relevant electrical resistance strain gauges. These are presented in Figs. 14 and 15. The following are the observations made:

SB1: While a flexural failure was expected for this beam, since the (a/d) value (i.e., 2.57) was close to the (a/d) value of 2.5 separating the flexural and shear failures, the strains recorded by the electrical strain gauges in the shear span region were examined (Fig. 14(a)). It may be noted that the spacing of the stirrups for this beam was 100 $\mathrm{mm}$ and that the shear span was $450 \mathrm{~mm}$. The sg1, sg2, sg5 and sg6 strain gauges were located in the shear span. It was noted that the $\operatorname{sg} 2$ and sg5 showed higher values of strain than the sg1 and sg6. Both the sg2 and sg5 strain gauges showed a similar trend (see Fig. 14(b)). Even though the sg5 showed a higher strain around the experimental peak load, the final failure occurred at a location nearer to the $\mathrm{sg} 2$.

SB2: The spacing of the stirrups for this beam was $120 \mathrm{~mm}$, and the shear span was $325 \mathrm{~mm}$. The sg1 and sg6 strain gauges were located in the shear span. It is noted that the sg1 and sg6 show higher values of strain (Fig. 14(c)) compared to the other strain gauges, which indicates that the strains that developed in the shear zone were significant. This was expected, since this beam was supposed to have a shear compression failure. It is also noted that the sg2 exhibited fewer fluctuations than the sg5 gauge (see Fig. 


\section{SIOYAMSJOUSSIAL Of $\mathrm{s}^{3}$

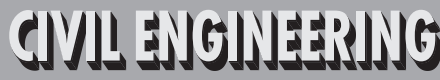

2012/3 PAGES $15-26$

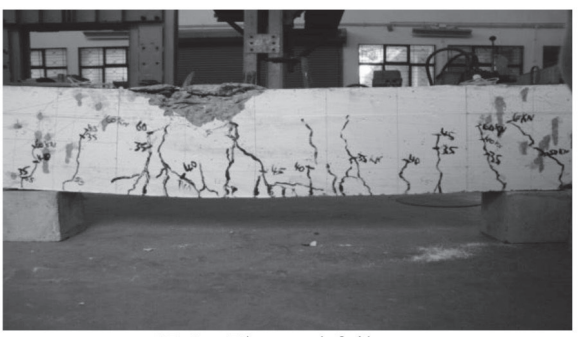

SB1 - Flexural failure

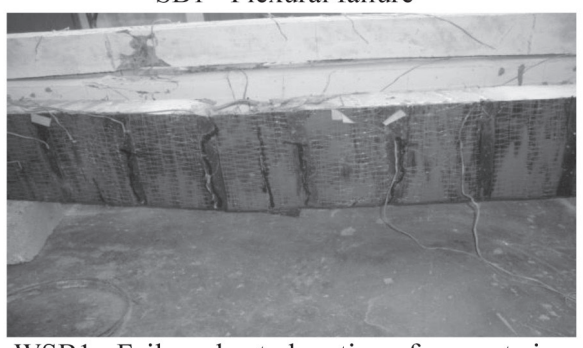

WSB1 - Failure due to bursting of concrete in compression near the load point (the hangar bar is buckled)

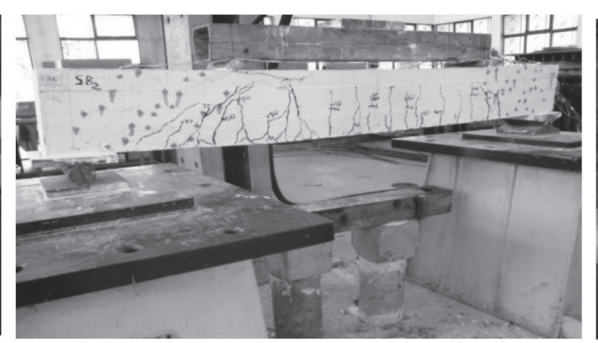

SB2 - Shear compression failure

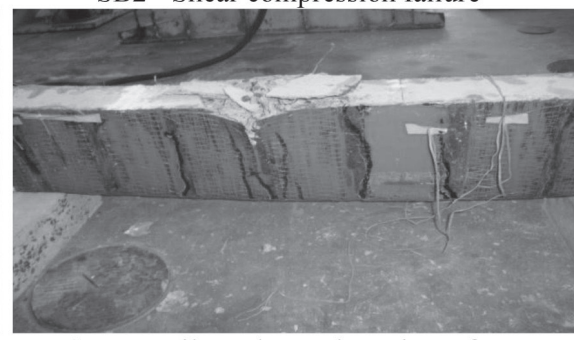

WSB2 - Failure due to bursting of concrete in the compression zone under one of the load points (the wrap did not separate from the concrete surface)

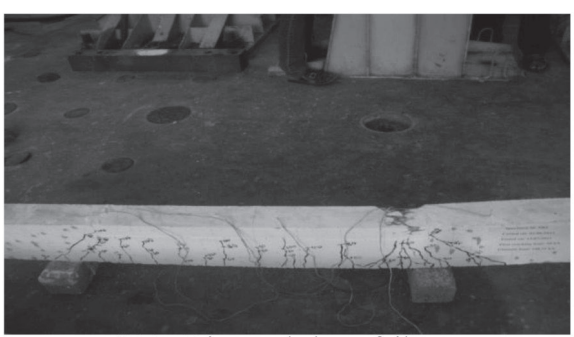

SB3 - Diagonal shear failure

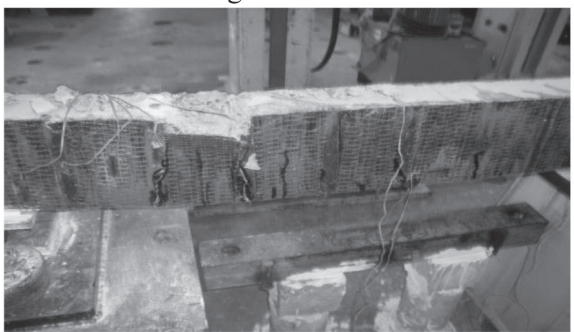

WSB3 - Failure due to theexplosive bursting of concrete in the compression zone under one of the load points (the CFRP might have gotten delaminated just before failure)

Fig. 13 Failure modes for the control beams and the three wrapped beams.

14(d)). Although the strains are approximately the same around the peak load (and the sg5 also showed a steep increase in strain), the sg2 relaxed, perhaps due to yielding or failure closer to this point. In fact, failure was noted under the load point closer to $\mathrm{sg} 2$.

SB3: The stirrup spacing was $125 \mathrm{~mm}$, and the shear span was 300 $\mathrm{mm}$ for this beam. The sg1 and sg6 strain gauges were located in the shear span. It was noted that the strains in the sg1 and sg2 exhibited a steep increase after a load of $60 \mathrm{kN}$ (see Fig. 14(e)). The strains recorded by these strain gauges were higher compared to the other strain gauges. This is because a diagonal tension (shear) failure was expected in this beam; hence, the strains that developed in the shear span region would be high. It can be seen in Fig. 14(f) that the sg5 recorded a steep increase in strain around the experimental peak load, which suggests that the failure occurred around the location of this strain gauge. The P- $\delta$ diagram of this specimen (Fig. 8) indicates that the section closer to $\mathrm{sg} 5$ was more flexible compared to the middle section and the section closer to sg2. In fact, as the $\mathrm{P}-\delta$ diagram indicates, the middle section of this beam was stiffer than the sections closer to the load points. The final failure of the beam occurred at a section closer to sg5 and closer to the load point.
WSB1: The sg3 and sg4 strain gauges, which were pasted on stirrups, were closer to the load points. The surfaces of the beam corresponding to the location of these embedded strain gauges were not wrapped. As expected, the sg3 and sg4 strain gauges were under tension. Fig. 15 shows that except at the peak load, the sg4 was relatively less strained compared to the sg3. When focusing on the sg10 and sg13 strain gauges, it can be seen that both of these strain gauges (which are on the surface of the concrete) were also under significant tension. The final crack pattern suggests that the cracks propagated vertically in the flexure zone. However, most of these cracks formed between the wraps. In some of the strips, although cracks (vertical) formed, they were not dominant. The final failure occurred due to the composite failure of the wrap and the concrete (together) in the flexure zone closer to a load point. After the composite failure, it seems the beam underwent out-of-plane bending/buckling.

WSB2: It is noted that, as in the case of the control beam (SB2), the $\operatorname{sg} 1$ and sg6 strain gauges showed higher strain values compared to the other electrical strain gauges (see Fig. 11). The strain variation with loading in the sg2 and sg5 strain gauges are shown in Fig. 15. The sg2 and sg5 strain gauges were pasted on stirrups and were

Tab. 4 Stiffness values $(\mathrm{kN} / \mathrm{mm})$ based on intial and second segments of $P$ - $\delta$ curves.

\begin{tabular}{|l|c|c|c|c|c|c|}
\hline Quantity & SB1 & WSB1 & SB2 & WSB2 & SB3 & WSB3 \\
\hline Stiffness before cracking & 48.39 & 83.33 & 50.0 & Very high & 50.0 & 100.0 \\
\hline Stiffness after cracking & 15.63 & 24.02 & 24.79 & 34.59 & 23.53 & 48.91 \\
\hline
\end{tabular}




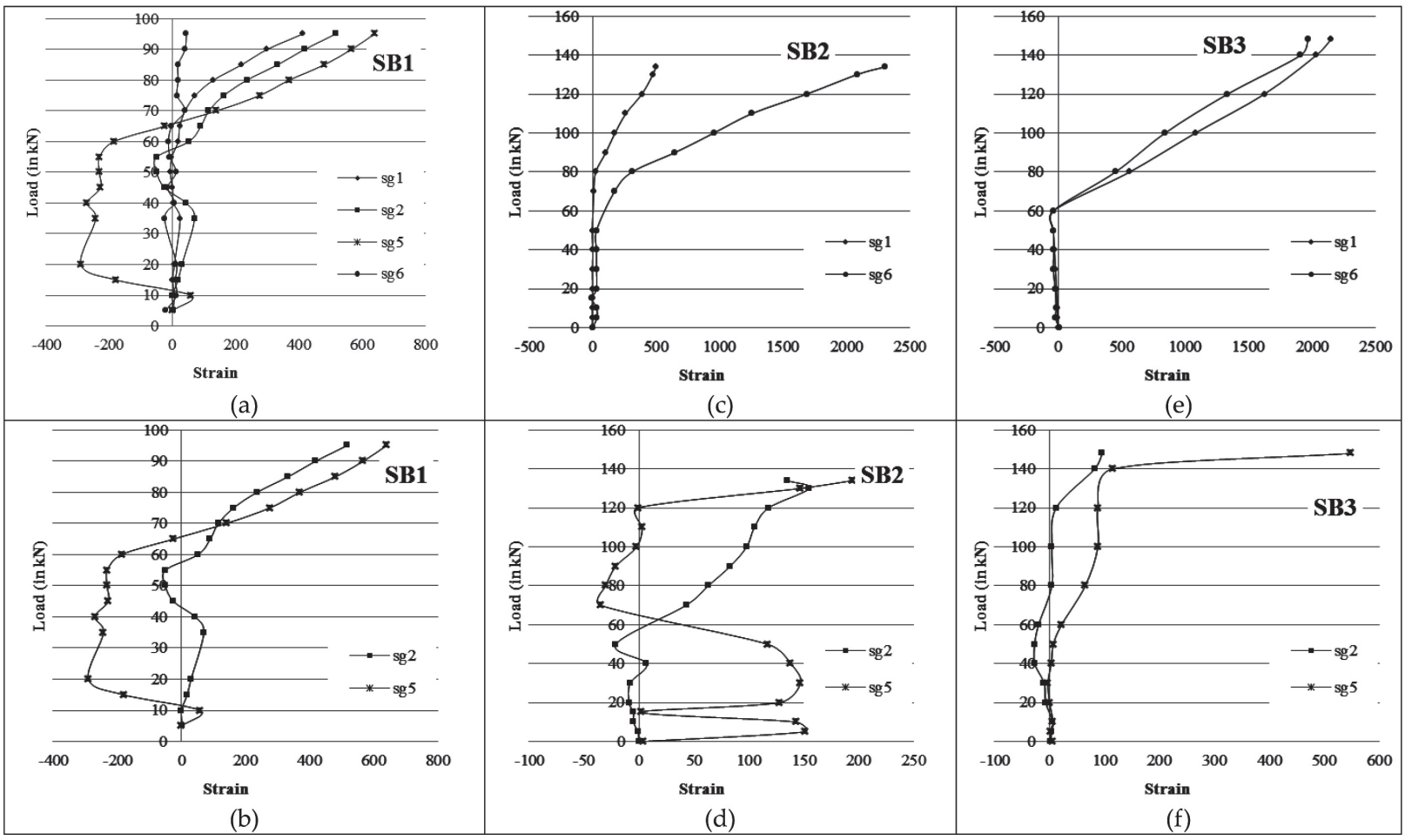

Fig. 14 Strain variations (in $\mu \varepsilon$ ) in electrical resistance strain gauges (located in the shear span region and located closer to the point loads) for the control beams (sg1, sg2 - north face; sg5, sg6 - south face; all the gauges on the stirrup; strains: positive-tension).

closer to the load points. These embedded strain gauges were at locations where the external surface of the concrete was wrapped. Fig. 15 shows that the sg5 was always in compression, while the sg2 gauge alternated between tension and compression. Close to the peak load, the sg2 gauge was under tension, which indicates a possible de-bonding and thus making the stirrup take the tension. In fact, the final de-bonding failure occurred near the sg2 gauge. When focusing on the surface pasted sg10, sg12 and sg13 strain gauges (which were on the surface of the concrete), it can be seen that the $\operatorname{sg} 10$ and $\operatorname{sg} 13$ were less strained compared to the $\operatorname{sg} 12$ (see Fig. 15). This beam developed significant flexural cracks in addition to the dominant crack under the load point before the wrap was de-bonded. The final failure pattern showed that the cracks propagated vertically both in between and within the wraps. However, the crack propagation within the wrap occurred near the failure zone. The final failure was due to the composite failure closer to a load point. It should be kept in mind that the $(\mathrm{a} / \mathrm{d})$ for this beam was 1.85 and that the SB2 failed in shear compression.

WSB3: The sg1 and sg6 strain gauges (located in the shear span region) showed higher strain values compared to the other electrical strain gauges (see Fig. 11), similar to what was observed for the
SB3 control beam. The strain variation with the loading in the sg2 and sg5 strain gauges are shown in Fig. 15. The sg2 and sg5 strain gauges were pasted on stirrups and were closer to the load points. These embedded strain gauges were situated at locations where the external surface of the concrete was wrapped. Fig. 15 shows that the sg5 was mostly in compression, while the sg2 was always under tension. The sg2 gauge near the peak load carried a higher degree of tension, which indicates a possible de-bonding and thus putting a demand on the stirrup to take the tension. In fact, the final de-bonding failure occurred near the sg2 gauge. When focusing on the surface pasted sg10, sg11 and $\operatorname{sg} 12$ strain gauges (the $\operatorname{sg} 11$ was on the wrap in the flexure zone, while the other two were on the surface of the concrete between the wraps), it is noted that the sg11 gauge was under a large degree of tension near the peak load and that the sg10 gauge was in compression, while the sg12 gauge was under tension at the peak load. The tension in the concrete indicated that the wrap had possibly de-bonded near this gauge. The final failure did occur under the point load closer to this gauge.

It was noted that for all the control beams and the wrapped beams except for the WSB1, the P- $\delta$ diagram could be idealised as a bi-linear curve, while for the WSB1, a tri-linear curve might be 


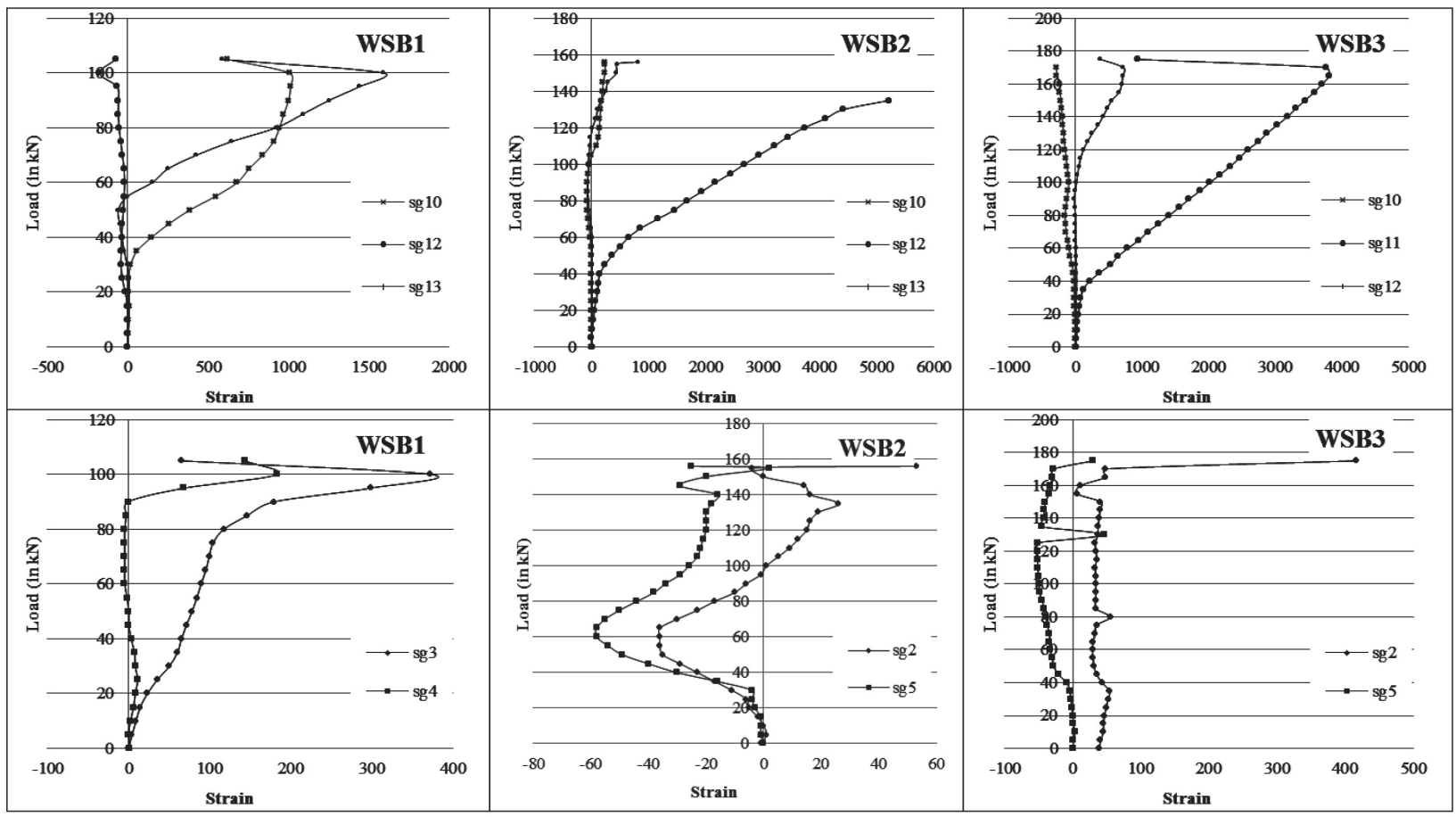

Fig. 15 Strain variations (in $\mu \varepsilon$ ) in the electrical resistance strain gauges (located closer to the centre of the beam and closer to the supports) for the wrapped beams (strains: positive - tension).

a better approximation. A careful study of the load-deflection curves of the control and wrapped beams (see Table 4) shows that with the wrapping, the stiffness values of all three beams almost doubled both before and after the cracking. Thus, while there may not have been a significant increase in strength, the serviceability control could be better exercised through wrapping.

\section{CONCLUSIONS}

Based on the experimental investigations carried out, the following general conclusions were drawn:

- The three control beams, each of which was designed to fail in a particular failure mode, behaved as expected.

- The wrapping scheme adopted in this study (i.e., discrete CFRP strips with fibres oriented at $90^{\circ}$ to a neutral plane) resulted in a change of failure mode from the shear to almost flexural mode. The CFRP wrapping and concrete was intact up to the failure of the beam, which clearly indicates the composite action was due to the CFRP wrap.

- The enhancement in the first crack load was $20-60 \%$, while that in the ultimate load was between 5-18\%, depending on the failure mode of the control beam.
- The load-deflection behaviour of the wrapped and the unwrapped beams considered in this investigation could be idealised by a bi-linear curve (at least up to the working load level).

- While the increase in strength was marginal, there was a significant improvement in the stiffness gained by the wrapping (it almost doubled, depending on the region of the load-deflection curve). This observation indicates that the wrapping scheme tested in this investigation could be used to satisfy the serviceability requirements and, to an extent, alter the failure mode.

- The strains measured both on the stirrups and on the surface of the beams using the electrical resistance strain gauges can be used to explain the behaviour of the beams up to failure. However, it has to be borne in mind that while the strain gauge measurements are point measurements, the load-deflection behaviour is an integral effect (hence the load-deflection curves are smooth).

These conclusions are based on investigations on only six beams; in order to generalise the conclusions, a greater number of tests for a given combination of variables may be needed. It is noted that the final failure of the wrapped beams occurred due to the de-bonding of the wrap in the compression zone at the critical point and that the failure was sudden. In order to avoid such failures, the use of a U-wrap in the form of strips with end anchors could possibly be explored. Also, there is a need to 
2012/3 PAGES $15-26$

study the efficacy of both discreet and continuous wrapping with a fibre orientation of $0^{\circ}$ to the neutral plane of the unloaded beam.

\section{Acknowledgements}

This paper is being published with the kind permission of the Director, CSIR-SERC, Chennai, India. The authors gratefully acknowledge the support extended by Dr. K. Ravisankar, Chief Scientist, Shri. K. Kesavan, Principal Scientist, and Ms. Pavitha of the Structural Health Monitoring Laboratory, CSIR-SERC. The authors are grateful to the members of the Advanced Materials Laboratory and Mr. Kumarappan, Senior Technical Officer, Structural Testing Laboratory, CSIR-SERC, for their unstinting help in carrying out the experimental work.

\section{REFERENCES}

[1] Khalifa A, Nanni A. Improving shear capacity of existing RC T-section beams using CFRP composites. Cement Concrete Comp 2000; 22:165-174.

[2] Khalifa A, Nanni A. Rehabilitation of rectangular simply supported RC beams with shear deficiencies using CFRP composites. Constr Build Mater 2002; 16(3):135-146.

[4] Saafan MAA. Shear strengthening of reinforced concrete beams using CFRP wraps. Acta Polytech 2006; 46(1):24-32.

[5] Anil Ö. Improving shear capacity of existing RCT-section beams using CFRP composites subjected to cyclic loading. Cement Concrete Comp 2006; 28:638-649.

[6] Pellegrino C, Modena C. Fiber-reinforced polymer shear strengthening of reinforced concrete beams: experimental study and analytical modelling. ACI Struct J 2006; 103(5):720-728.

[7] Bousselham A, Chaallal O. Shear strengthening reinforced concrete beams with fiber-reinforced polymer: assessment of influencing parameters and required research. ACI Struct J 2004; 101:219-227.

[8] Rabinovitch O, Frostig Y. Experiments and analytical comparison of RC beams strengthened with CFRP composites. Compos Part B-Eng 2003; 34(8):663-677.

[9] Jayaprakash J, Abdul Samad AA, Ashrabov AA, Chong KK. Experimental investigation on shear resistance behaviour of RC precracked and non-precracked T-beams using discrete CFRP strips. Int J Integ Eng 2009; 1(2):1-15.

[10] Lakshmanan N, Krishnamoorthy TS, Balasubramanian K, Baharatkumar BH, Gopalakrishnan S. Investigations on the Flexural Behaviour of Retrofitted Reinforced Concrete Beams. Report prepared for Department of Science and Technology, Government of India, New Delhi, SERC Report No. GAP-01741-RR-2004-1. Chennai: CSIR-Structural Engineering Research Centre 2004.

[11] Ramana VPV, Kant T, Morton SE, Dutta PK, Mukherjee A, Desai YM. Behavior of CFRPC strengthened reinforced concrete beams with varying degrees of strengthening. Compos Part B-Eng 2000; 31:461- 470
[12] Pendhari SS, Kant T, Desai YM. Application of polymer composites in civil construction: a general review. Compos Struct 2008; 84(2):114-124.

[13] Hagio H, Katsumata H, Kimura K. The beam retrofitted by carbon fiber - experiment and designs. In: Proceedings of $12^{\text {th }}$ World Conference on Earthquake Engineering. Auckland, New Zealand 2000. Paper No. 451.

[14] Li A, Diagana C, Delmas Y. CFRP contribution to shear capacity of strengthened RC beams. Eng Struct 2001; 23:1212-1220

[15] Shahawy MA, Arockiasamy M, Beitelman T, Sowrirajan R. Reinforced concrete rectangular beams strengthened with CFRP laminates. Compos Part B-Eng 1996; 27(3-4):225-233

[16] Chajes MJ, Januzska TF, Mertz DR, Thomson TA Jr, Flench WW Jr. Shear strengthening of reinforced concrete beams using externally applied composite fabrics. ACI Struct J 1995; 92(3):295-303.

[17] Fyfe ER, Gee DJ, Milligan PB. Composite systems of seismic applications. Concrete Int 1998; 20(6):31-33.

[18] Khalifa A, Gold W, Nanni A, Abel-Aziz M. Contribution of externally bonded FRP to the shear capacity of RC flexural members. J Compos Constr 1998; 2(4):195-203.

[19] Sheheta E, Morohy R, Rizkalla S. Use of FRP as shear reinforcement for concrete structures. In: Eshani MR, Saadatmanesh H Editors. Proceedings of ICCI '98, 1998, pp. 300-315.

[20] ACI SP-138. Shear Capacity of RC and PC Beams Using FRP Reinforcement. Detroit, MI: American Concrete Institute, 1993.

[21] NCHRP Report 514. Bonded Repair and Retrofit of Concrete Structures Using FRP Composites: Recommended Construction Specifications and Process Control Manual. Washington DC: Transportation Research Board, 2004.

[22] BIS. Indian Standard Code of Practice for Plain and Reinforced Concrete, IS 456: 2000. New Delhi: Indian Standards Institution, 2000. 